\title{
Comparison of AIRGrav and GT-1A airborne gravimeters for research applications
}

\author{
Michael Studinger ${ }^{1}$, Robin Bell ${ }^{1}$, and Nick Frearson ${ }^{1}$
}

\begin{abstract}
Airborne gravimetry has played a vital role in contributing to our knowledge of the subglacial environment in polar regions. Previous programs have produced extensive gravity data sets in Antarctica, but the resolution and accuracy of the data have been limited. We have evaluated the relative performance and suitability of two different airborne gravimeters for research applications from flight tests over the Canadian Rocky Mountains near Calgary. Survey design, mission profiles, and demands on the performance of an airborne gravimeter are different for the remote polar environment than for most commercial exploration surveys. Both systems, the AIRGrav and GT-1A, can produce higher-resolution data with improved flight efficiency than can the BGM-3 and LaCoste \& Romberg gravimeters used in Antarctica. The AIRGrav and GT-1A systems are capable of draped flying of airborne gravity, allowing new applications for polar use. Both systems could provide the academic community with a significant increase in accuracy and horizontal resolution to enable major advances in understanding the subglacial environment. Compared to the GT-1A system, the AIRGrav system has a lower noise level and higher accuracy, and it is less sensitive to changing flight conditions - in particular, vertical accelerations during turbulent flights.
\end{abstract}

\section{INTRODUCTION}

The polar regions, key elements in the earth's geodynamic and climatic systems, are very sensitive to global environmental changes and have the potential to trigger significant global sea-level rise as large volumes of ice melt. Locked within these icy regions are the records of past global climate shifts and enigmatic ecosystems, sealed from open interactions with the atmosphere for millions of years. Although space-based remote-sensing tools can image the surface of the polar ice sheets, many key processes are impossible to image from space and can be examined only through airborne- or surface-based geophysical instrumentation. Instrumented aircraft are essential for studying the vast expanses of snow and ice of the Antarctic continent, the subcontinent of Greenland, and the surrounding oceans.

As a first step toward developing a new generation of aerogeophysical imaging systems for polar applications, we tested two different airborne gravimeters on a Twin Otter aircraft with a side-byside installation. We first evaluated the gravimeters' performance over a known test range near Calgary and the Rocky Mountains, then at a higher latitude out of Eureka, Ellesmere Island $\left(80^{\circ} \mathrm{N}\right)$, to the North Pole. Results from the Rocky Mountains test flights form the basis of this paper. The Arctic flights will be discussed in a separate paper.

Airborne gravimetry has been essential in studying the subglacial environment in Antarctica. Between 1977 and 1989, Sevmorgeologia conducted the first airborne gravity surveys in the Weddell Sea under the auspices of the Soviet Antarctic Expedition (Aleshkova et al., 2000). More than 70,000 km of aerogravity data were collected from an Ilyushin IL-14 aircraft. In the 1980s, the Naval Research Laboratory and Lamont-Doherty Earth Observatory of Columbia University conducted a major airborne gravity survey through a series of P-3 Orion flights into the Weddell Sea (Brozena et al., 1987; Bell et al., 1990). During the 1990s, the Support Office for Aerogeophysical Research (SOAR), a joint facility between the University of Texas Institute for Geophysics, the Lamont-Doherty Earth Observatory of Columbia University, and the U. S. Geological Survey under a cooperative agreement with the U. S. National Science Foundation (e.g., Brozena et al., 1993; Bell et al., 1999; Blankenship et al., 2001), collected more than $275,000 \mathrm{~km}$ of data from a DHC-6 Twin Otter aircraft using either a Bell Aerospace BGM-3 marine gravimeter or a LaCoste \& Romberg S-gravimeter modified by the ZLS Corporation.

Similar projects by the British Antarctic Survey and the Alfred Wegener Institute for Polar and Marine Research, Germany, have utilized LaCoste \& Romberg air/sea gravimeters on Twin Otter and

Manuscript received by the Editor 26 March 2008; published online 24 October 2008.

${ }^{1}$ Lamont-Doherty Earth Observatory of Columbia University, Palisades, New York, U.S.A. E-mail: mstuding@1deo.columbia.edu; robinb@1deo.columbia. edu;nfre@1deo.columbia.edu.

(C) 2008 Society of Exploration Geophysicists. All rights reserved. 
Dornier DO-228 aircraft, respectively (Boebel, 2000; Jones et al., 2002). In 2002 and 2003, a joint project between the German Federal Institute for Geoscience and Natural Resources (BGR) and the Australian Antarctic Division (AAD) used a ZLS Ultra-Sys LaCoste \& Romberg air/sea gravimeter on a Twin Otter aircraft to collect data over the southern Prince Charles Mountains and Lambert Glacier area (Damaske and McLean, 2005; McLean and Reitmayr, 2005).

Although all of these programs have produced extensive gravity data sets in Antarctica, the resolution and accuracy of the data have been limited. The requirement for survey lines extending beyond the target area and the inability of the systems to accommodate draped survey flights has prevented the broader application of aerogeophysical data to polar science questions.

\section{TEST DESCRIPTION}

\section{Gravimeter systems}

The principal goal of an extensive flight test program in May and June 2007 was to compare different airborne gravimeter systems with the potential of producing higher-resolution data in polar regions along with improving flight efficiency. We evaluated two gravimeters, a Sander Geophysics Ltd. (SGL) AIRGrav (airborne inertially referenced gravimeter) and a Canadian Micro Gravity Pty. Ltd. (CMG) GT-1A system on a DHC-6 Twin Otter aircraft. The side-by-side installation and operation of these two systems provides a unique opportunity to evaluate their relative performance for the first time.

The Sander Geophysics AIRGrav system consists of a three-axis stabilized inertial platform utilizing three orthogonal accelerometers and two two-degrees-of-freedom gyroscopes (Sander et al., 2004, and references therein). The platform is controlled in free inertial mode with Schuler tuning, such that the sensor block holding the accelerometers and gyroscopes is held within 10 arc-s $\left(0.0028^{\circ}\right)$ of local level at all times. This platform design ensures that the vertical accelerometer remains oriented very close to the direction of the gravity vector, independent of aircraft maneuvers. The vertical accelerometer can be used alone as a scalar gravity sensor; however, the accelerometers and gyroscopes are precise enough to extract vector gravity components with suitable postprocessing.

The CMG GT-1A is an airborne, single-sensor, vertical scalar GPS-INS gravimeter with a Schuler-tuned three-axis inertial platform (Gabell et al., 2004, and references therein). A turntable provides the platform's azimuth axis control. The gravimeter was developed by Joint Stock Company Gravimetric Technologies in the Russian Federation. The postprocessing software was developed by the Lomonosov Moscow State University's Department of Mechanics and Mathematics. The GT-1A is made available outside the Russian Federation by CMG.

Both gravimeters were installed near the aircraft's center of gravity on a 30-cm-high rack mounted to the floor of the cabin to accommodate both gravimeters in the wider fuselage section. Although the rack was bolted to the floor and the sidewalls of the main cabin, this installation may have introduced additional noise compared to an installation fixed firmly into the seat rails of the cabin floor. Three global positioning system (GPS) antennas were mounted on top of the fuselage. Two antennas were located approximately above the gravimeters, and a third antenna was mounted approximately $3 \mathrm{~m}$ aft of the gravimeters for use in the AIRGrav high-latitude tests. The AIRGrav system utilized two Antcom Corporation GPS antennas (model 3G-1215A-XT-1), and the GT-1A system used a single AeroAntenna Technology GPS antenna (model AT2775-41).

\section{Test flight program}

The test flights over several repeat ground tracks were conducted in May and June 2007 from Calgary, Canada. The area covered by the flight paths includes the foothills of the Rocky Mountains near Turner Valley and the rugged topography of the mountain range (Figure 1). The free-air gravity field over the test area generally strikes north to south and varies from very smooth, low-amplitude anomalies over the foothills region to very large, high-amplitude, short-wavelength anomalies (Canadian Geodetic Information System, 2008).

The two main flight lines were a 100-km-long east-west line (line 200, Figure 2) and a 180-km-long north-south line (line 400, Figure $3)$. The east-west line was flown over existing ground and airborne gravity measurements for comparison. The long north-south line over the rugged mountain topography provides different environments for gravimeter testing. In total, more than $1600 \mathrm{~km}$ of data were collected during this campaign (Table 1). The topography changes more than $1500 \mathrm{~m}$ along these profiles, making it an ideal setting for a draped survey design.

Two GPS ground stations were operated during the flights for differential positioning: one at the Calgary airport for the AIRGrav system and one at the Airdrie airport for the GT-1A system, as requested by the respective operators (Figure 1). Target flying altitude varied between 1900 and $3250 \mathrm{~m}$, with constant climb and descent rates between waypoints (Figures 2 and 3). Average ground speed of the aircraft was $76 \mathrm{~m} / \mathrm{s}$. Flights in the early morning and late evening were generally smoother than flights during the day because of air turbulence over the mountain range. During the day, vertical aircraft accelerations reached up to $2.9 \mathrm{~m} / \mathrm{s}^{2}$ at $2 \mathrm{~Hz}$ (Table 1 ).

\section{COMPARISON BETWEEN REFLIGHTS}

\section{Difference between passes}

The accuracy and internal consistency of the aerogravity measurements can be assessed from differences between reflights (passes) of the same line. To estimate the noise, we calculate the root mean square (rms) of the differences between all reflights divided by $\sqrt{2}$. For comparison, we also estimate the noise using the method advanced by Green and Lane (2003). This method is based on a linear model for additive errors that are a function of the line $l$ and sample $i$. The data $X_{l, i}$ are used to calculate the arithmetic mean for each line $\left(X_{D, i}\right)$, the arithmetic mean for each location $\left(X_{l, D}\right)$ using all lines, and the arithmetic mean of the entire data set $\left(X_{D, D}\right)$. The residual $D_{l, i}$ $=X_{l, i}-X_{D, i}-X_{l, D}+X_{D, D}$ is then used to calculate the standard deviation $\sigma$ of the noise.

Before assessing the differences between passes, the data along individual flight lines were interpolated onto common ground points spaced $25 \mathrm{~m}$ apart and upward/downward continued to a standard target flight elevation. The noise estimate is based on reflight lines for the two systems. Several passes were excluded from the comparison because vertical accelerations during flight exceeded the $\pm 0.5 \mathrm{~m} / \mathrm{s}^{2}$ operational limit of the GT-1A or did not pass CMG's established quality-control (QC) criteria. In particular, all passes of line 300, a 60-km-long line over rugged topography, were excluded because either the GT-1A operational limits were exceeded or the 
GT-1A data did not meet the CMG QC criteria. The selected lines and passes are listed in Table 1, together with the reasons for excluding several lines from the analysis.

We evaluated noise estimates for 70-, 100-, and 140-s low-pass filtered data (Figure 4). The noise in both systems shows the typical decrease with longer cutoff wavelengths. The noise estimates of the AIRGrav system cluster closely for lines 100, 200, and 300 (Figure $4 \mathrm{a}$ and $\mathrm{c}$ ), suggesting that the system noise is largely independent from varying conditions such as turbulence and changes in flight elevation during draped survey flying (Argyle et al., 2000). The noise in the GT-1A system for lines 200 and 400 varies significantly between the three lines (Figure $4 b$ and d), which likely reflects different performance of the system in different conditions. For both systems, noise estimated using the Green and Lane (2003) method utilized by CMG (Figure $4 \mathrm{c}$ and $\mathrm{d}$ ) shows smaller values than the commonly used rms of the differences divided by $\sqrt{2}$ (Figure $4 a$ and $b$ ).
Tests with synthetic data reveal that the lower noise estimates of the Green and Lane (2003) method are an intrinsic bias of this method for small numbers of reflights. Noise estimates based on synthetic data for the rms method were generally independent of the number of reflights used, whereas the Green and Lane noise estimates were consistently lower and more sensitive to the number to reflights (Figure 5). The experiment was repeated $10^{4}$ times and averaged, and the estimates were normalized. This experiment demonstrates that for a small number of reflights, the Green and Lane (2003) method produces significantly lower noise estimates than the rms differences between reflights.

\section{Frequency content}

Each system uses a different low-pass filtering schema. The fundamental difference in filtering could affect the comparison of noise
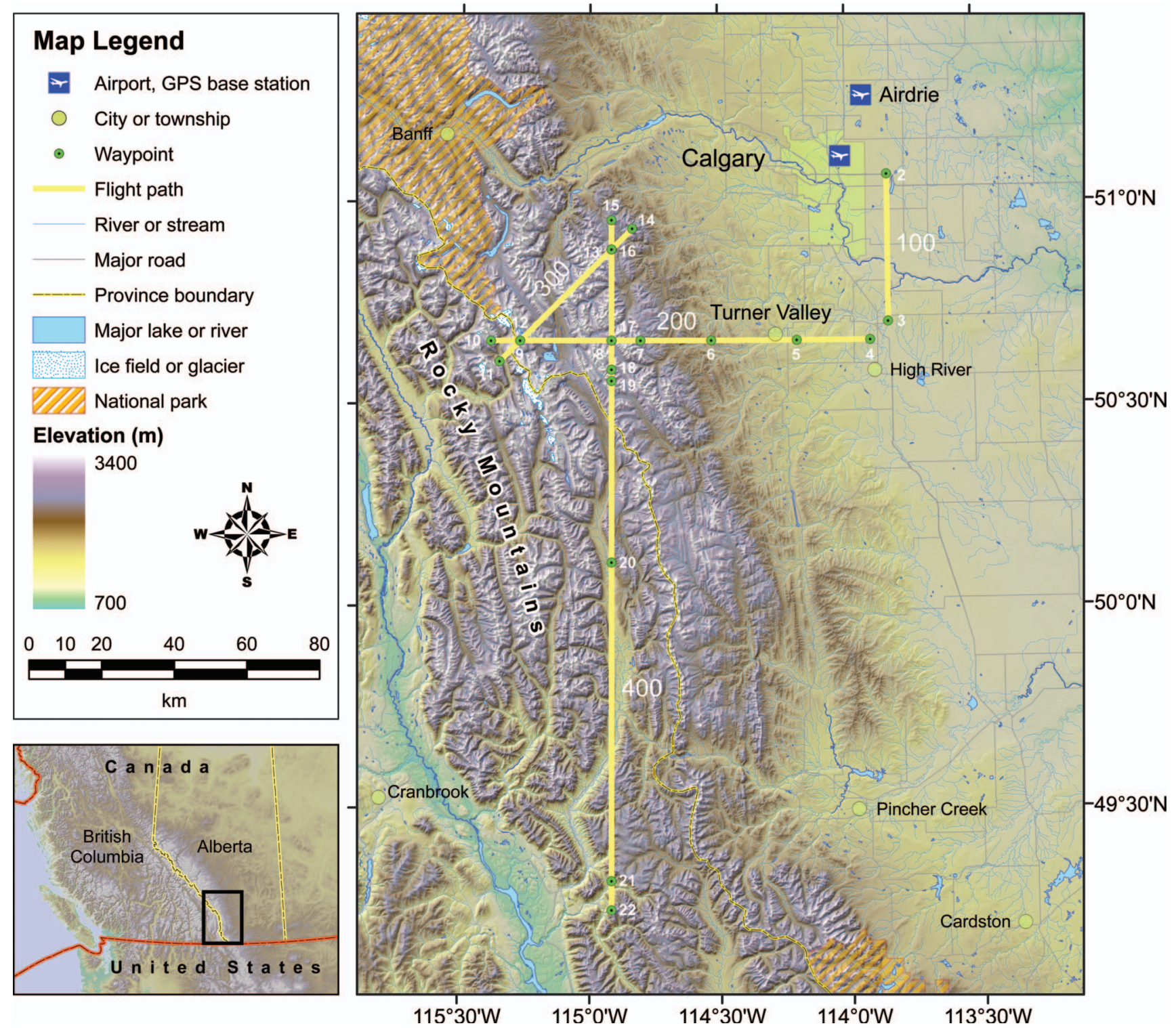

Figure 1. Location of gravimeter test flights (yellow lines) over the Rocky Mountains, Canada. Line 200 is the east-west line over Turner Valley with well-documented existing gravity data sets, both airborne and ground. Line 400 is the long north-south line over the higher elevation that replicates operations over rugged topography. Shaded relief is 3 arc-s (i.e., 90-m) digital elevation model produced from the Shuttle Radar Topography Mission (SRTM) data. 
estimates. The AIRGrav data were filtered using a cosine taper in the frequency domain, with the filter cutoff length corresponding to the half-point in the transfer function. For the GT-1A, a Kalman filter was applied to the data. The GT-1A Kalman filter has transfer function characteristics similar to the cosine taper used for the AIRGrav system (Gabell et al., 2004). Noise in aerogravity data generally decreases toward longer wavelengths (Figure 4), and for this reason the frequency content of the filtered data needs to be analyzed for comparison.
Figure 6 shows the averaged power-spectral-density estimates for the data low-pass filtered with $100 \mathrm{~s}$ that have been used to estimate the noise. Data from line 100 have been excluded from this analysis because the line is too short $(24 \mathrm{~km})$ to compute a power spectrum. We use the time-series data at flight elevation to avoid potential alteration of the frequency content of the gravity signal from spatial interpolation and upward continuation. Power spectra have been estimated for each pass using a multitaper method (Thomson, 1982) and then averaged. Because the signal-to-noise ratio increases by $\sqrt{N}$

a)

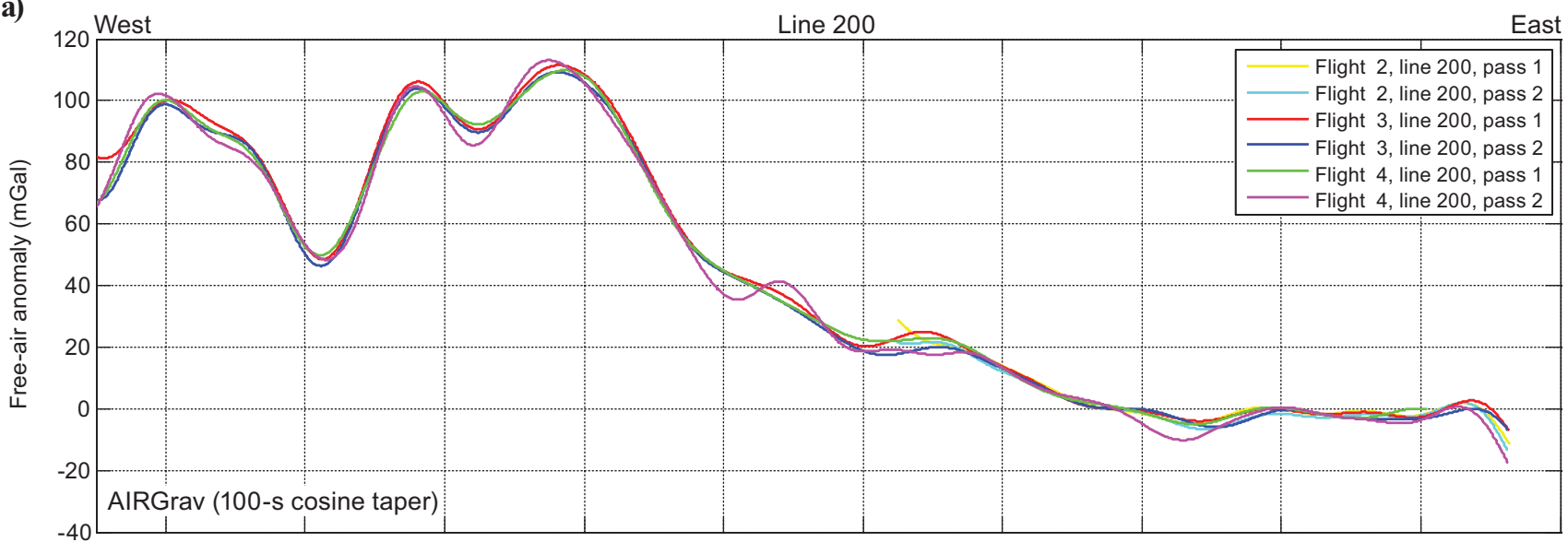

b)

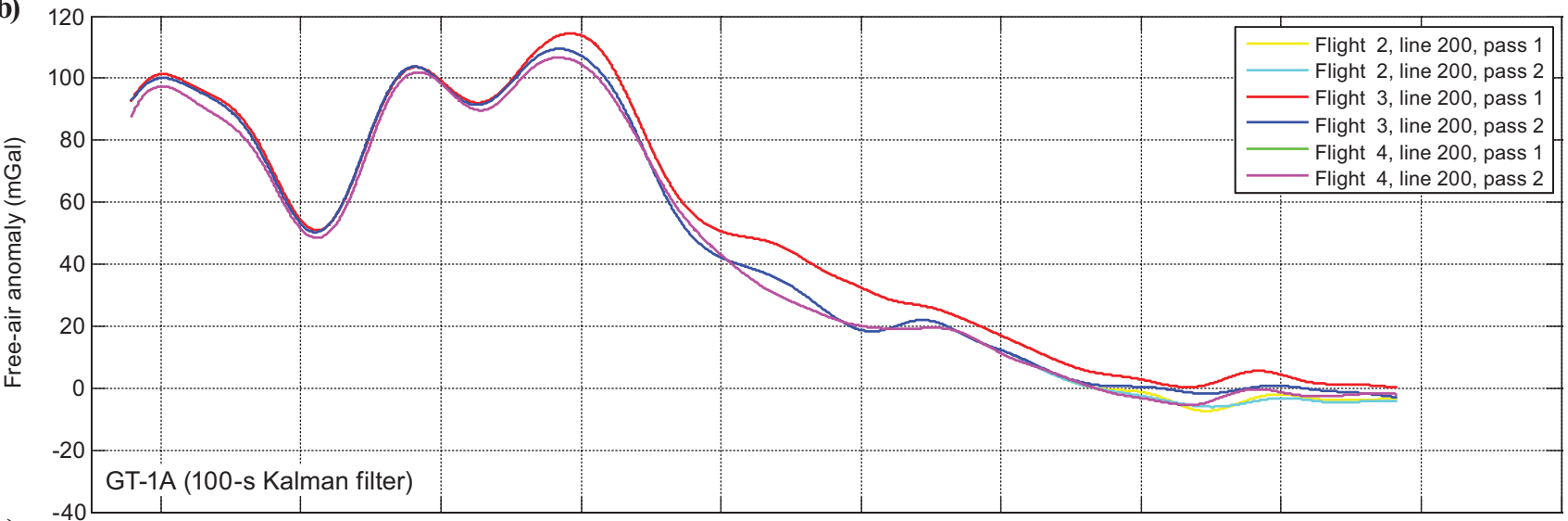

c)

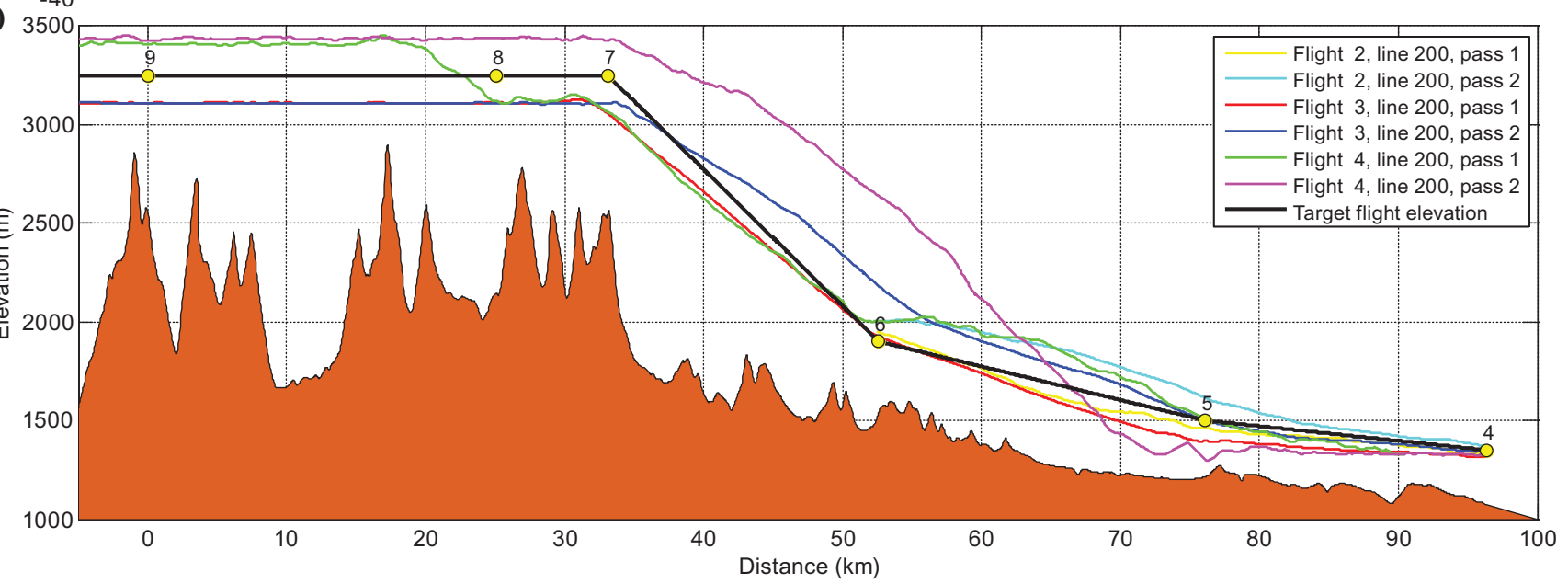

Figure 2. Free-air gravity at target flight elevation for east-west line 200. (a) AIRGrav low-pass filtered with 100-s cosine taper. (b) GT-1A filtered with 100-s Kalman filter. Data recorded on flight 4, pass 1, exceeded the operational limits and did not satisfy CMG's quality criteria. (c) Flight elevations and topography along flight paths. 
during the averaging, it is unlikely that noise contributes significaly to the amplitudes of the averaged gravity power spectrum. For wavelengths greater than $400 \mathrm{~s} \mathrm{(30} \mathrm{km} \mathrm{at} 75 \mathrm{~m} / \mathrm{s}$ flying speed), the AIRGrav system reveals larger amplitudes in the power spectrum (Figure $6 \mathrm{a})$. Between $200 \mathrm{~s}(15 \mathrm{~km})$ and $400 \mathrm{~s}$, the amplitudes in both systems are similar. Below $180 \mathrm{~s}$, amplitudes in the AIRGrav system are higher than for the GT-1A (Figure 6b).

To reveal the impact of the low-pass filters on the frequency content of the gravity data, the same cosine taper low-pass filter used for the AIRGrav data was applied to the GT-1A unfiltered free-air gravity (Figure 7). The 100-s Kalman filtered gravity of the GT-1A system shows smaller peak-to-peak amplitudes than the AIRGrav system, consistent with the smaller amplitudes in the averaged power spectrum. Filtering the GT-1A gravity with the 100-s cosine taper increases the GT-1A amplitudes to the AIRGrav levels. The same effect is evident in the spectral analysis. The 100-s Kalman filter suppresses more high-frequency signal than the 100-s cosine taper and thus removes more high-frequency noise from the data than the co-

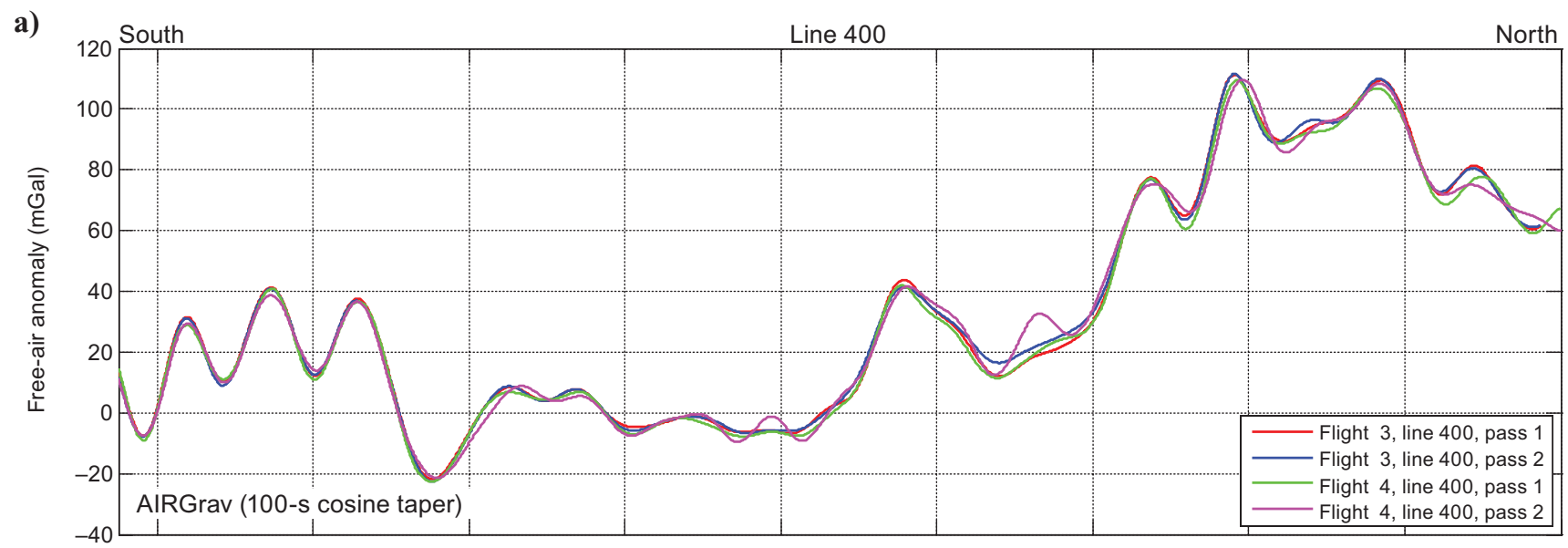

b)

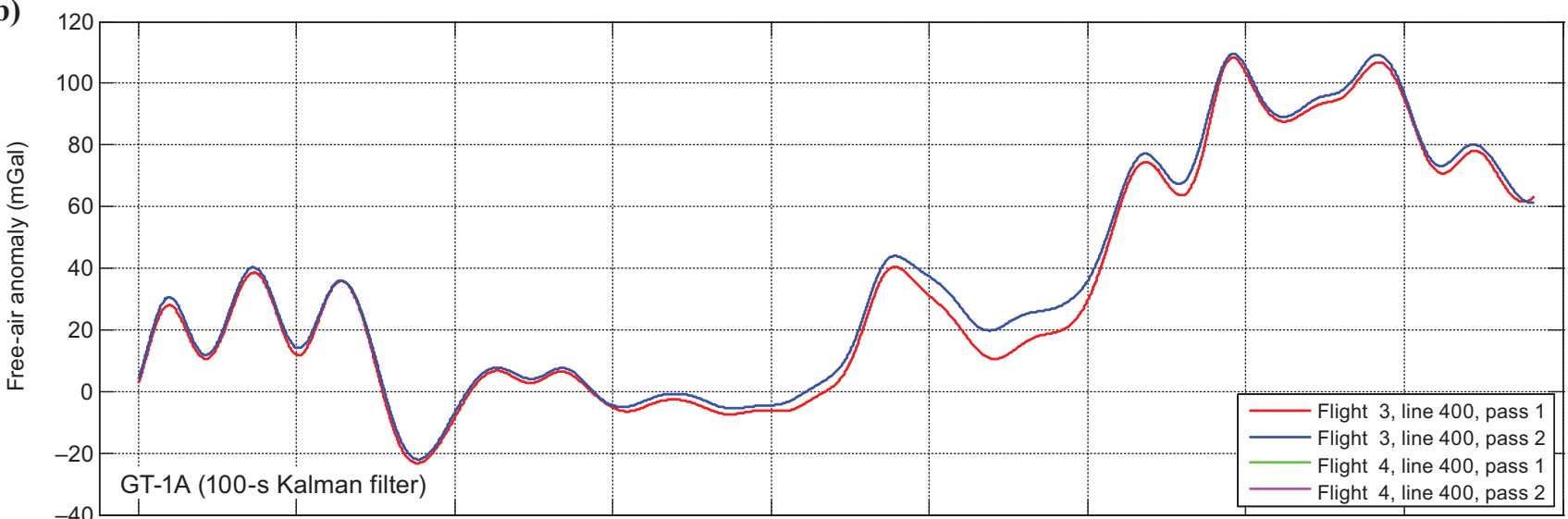

c)

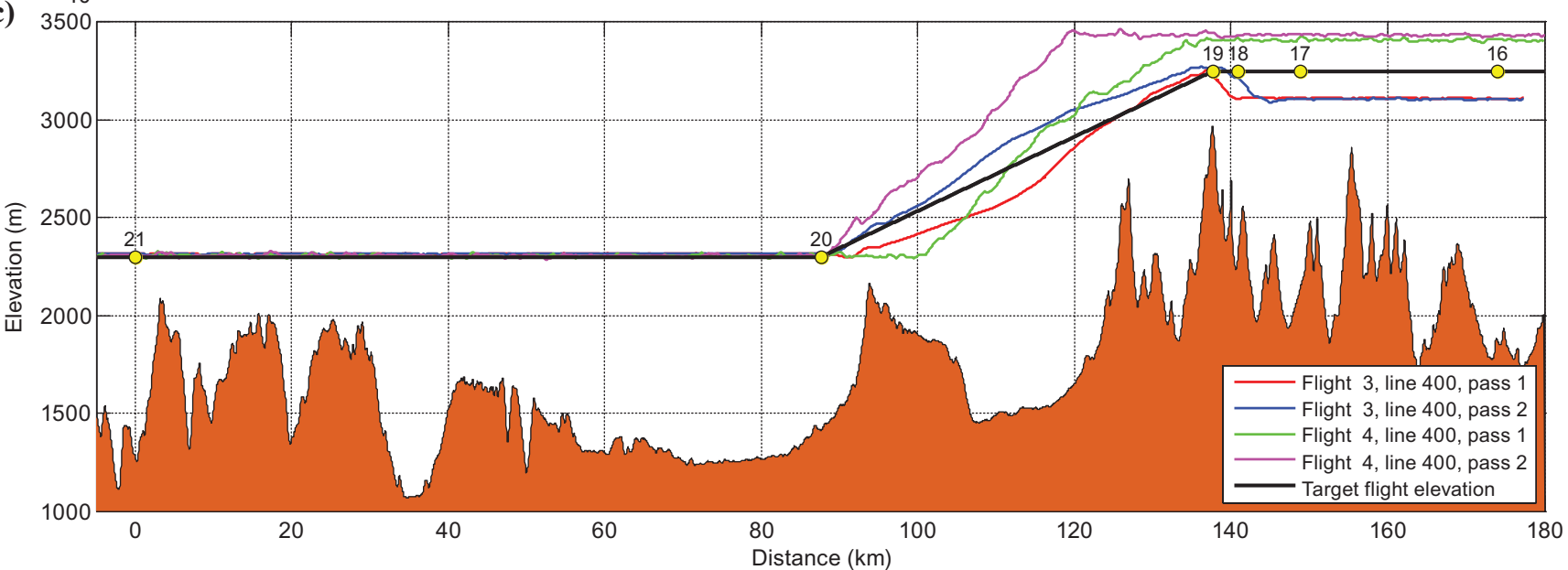

Figure 3. Free-air gravity at target flight elevation for north-south line 400. (a) AIRGrav low-pass filtered with 100-s cosine taper. (b) GT-1A filtered with 100-s Kalman filter. Data recorded on flight 4 exceeded the operational limits and did not pass CMG's quality criteria. (c) Flight elevations and topography along flight paths. 


\begin{tabular}{|c|c|c|c|c|c|c|c|c|c|c|c|c|c|c|c|c|}
\hline \multirow[b]{2}{*}{ Line } & \multirow[b]{2}{*}{ Flight } & \multirow[b]{2}{*}{ Pass } & \multicolumn{3}{|c|}{$\begin{array}{c}\text { Vertical acceleration } \\
\left(\mathrm{m} / \mathrm{s}^{2}\right) \text { at } 2 \mathrm{~Hz} \text { from DGPS }\end{array}$} & \multicolumn{3}{|c|}{$\begin{array}{c}\text { Horizontal } \\
\text { line deviation }(\mathrm{m})\end{array}$} & \multicolumn{3}{|c|}{$\begin{array}{c}\text { Vertical } \\
\text { line deviation }(\mathrm{m})\end{array}$} & \multicolumn{2}{|c|}{ Usable line $(\mathrm{km})$} & \multicolumn{2}{|c|}{$\begin{array}{l}\text { Validation: }(\boldsymbol{}) \\
\text { Reject }(\times)\end{array}$} & \multirow{2}{*}{$\begin{array}{l}\text { Reason for } \\
\text { excluding } \\
\text { from reflight } \\
\text { comparison } \\
\text { and noise } \\
\text { estimates }^{\mathrm{a}}\end{array}$} \\
\hline & & & $\max$ & $\min$ & $\mathrm{rms}$ & $\max$ & $\min$ & $\begin{array}{l}\text { sta. } \\
\text { var. }\end{array}$ & $\max$ & $\min$ & $\begin{array}{l}\text { sta. } \\
\text { var. }\end{array}$ & AIRGrav & GT-1A & AIRGrav & GT-1A & \\
\hline 100 & 2 & 1 & 0.56 & -0.80 & 0.17 & 55.8 & -54.2 & 12.4 & 26.6 & 18.3 & 1.2 & 34.2 & 24.4 & $(\mathcal{})$ & $(\mathscr{\checkmark})$ & \\
\hline 100 & 2 & 2 & 0.56 & -0.60 & 0.12 & 28.6 & -52.9 & 10.6 & 27.3 & 22.6 & 0.9 & 39.0 & 24.4 & $(\mathcal{})$ & $(\checkmark)$ & \\
\hline 100 & 3 & 1 & 0.20 & -0.24 & 0.06 & 204.5 & 23.6 & 64.3 & 42.9 & 39.6 & 0.6 & 40.4 & 24.4 & $(\checkmark)$ & $(\mathcal{})$ & \\
\hline 100 & 3 & 2 & 0.80 & -0.96 & 0.27 & 50.2 & -30.4 & 13.3 & 28.3 & 17.5 & 1.7 & 23.2 & 14.7 & $(\sqrt{ })$ & $(\checkmark)$ & Shortened $^{\mathrm{b}}$ \\
\hline 100 & 4 & 1 & 1.80 & -2.08 & 0.63 & 22.6 & -31.3 & 8.2 & 31.8 & 9.1 & 4.8 & 40.5 & 24.4 & $(\checkmark)$ & $(\mathcal{\checkmark})$ & \\
\hline 100 & 4 & 2 & 1.80 & -2.16 & 0.56 & 39.9 & -37.8 & 13.1 & 34.2 & 9.8 & 5.0 & 40.5 & 24.4 & $(\boldsymbol{})$ & $(\boldsymbol{J})$ & \\
\hline 200 & 2 & 1 & 0.64 & -0.60 & 0.21 & 25.4 & -23.9 & 8.5 & 77.4 & -46.2 & 30.0 & 43.9 & 27.7 & $(\mathcal{})$ & $(\mathcal{\checkmark})$ & Short line \\
\hline 200 & 2 & 2 & 0.72 & -0.68 & 0.16 & 125.1 & -13.3 & 25.2 & -19.8 & -187.5 & 62.4 & 43.8 & 27.7 & $(\mathcal{})$ & $(\checkmark)$ & Short line \\
\hline 200 & 3 & 1 & 0.76 & -0.56 & 0.11 & 100.6 & -201.7 & 50.4 & 195.5 & -23.1 & 47.9 & 101.4 & 90.4 & $(\boldsymbol{\checkmark})$ & $(\boldsymbol{\checkmark})$ & \\
\hline 200 & 3 & 2 & 1.16 & -1.32 & 0.23 & 22.4 & -67.7 & 13.0 & 147.6 & -281.5 & 129.5 & 101.3 & 90.4 & $(\mathscr{\checkmark})$ & $(\checkmark)$ & \\
\hline 200 & 4 & 1 & 2.88 & -2.76 & 0.62 & 51.1 & -54.8 & 14.0 & 186.7 & -203.9 & 123.7 & 98.5 & - & $(\mathcal{})$ & $(\times)$ & Incomplete $^{\mathrm{c}}$ \\
\hline 200 & 4 & 2 & 2.88 & -2.36 & 0.54 & 120 & -110.5 & 30.2 & 231.4 & -737.5 & 266.8 & 103.0 & 90.4 & $(\boldsymbol{})$ & $(\boldsymbol{})$ & $\begin{array}{l}\text { Vertical line } \\
\text { deviation }\end{array}$ \\
\hline 300 & 3 & 1 & 0.64 & -0.60 & 0.12 & 46.1 & -66.9 & 16.7 & 143.8 & 134.5 & 1.4 & 36.3 & - & $(\mathcal{})$ & $(\times)$ & Incomplete $^{\mathrm{c}}$ \\
\hline 300 & 3 & 2 & 1.44 & -2.16 & 0.26 & -0.5 & -59.4 & 8.9 & 148.8 & 134.4 & 1.9 & 40.5 & - & $(\mathcal{\checkmark})$ & $(\times)$ & Incomplete $^{c}$ \\
\hline 300 & 4 & 1 & 1.60 & -1.88 & 0.57 & 17.7 & -55.3 & 15.5 & -143.4 & -182.8 & 6.1 & 51.4 & - & $(\boldsymbol{\checkmark})$ & $(\times)$ & Incomplete $^{c}$ \\
\hline 300 & 4 & 2 & 2.80 & -2.28 & 0.7 & 30.0 & -25.4 & 12.2 & -169.3 & -207.2 & 5.9 & 46.2 & - & $(\mathcal{})$ & $(\times)$ & Incomplete $^{c}$ \\
\hline 400 & 3 & 1 & 0.80 & -0.80 & 0.11 & 23.6 & -34.2 & 6.5 & 163.6 & -34.6 & 70.4 & 186.0 & 176.3 & $(\mathcal{J})$ & $(\checkmark)$ & \\
\hline 400 & 3 & 2 & 1.24 & -1.56 & 0.19 & 23.9 & -24.0 & 7.7 & 159.5 & -143.2 & 78.4 & 186.0 & 176.3 & $(\boldsymbol{\checkmark})$ & $(\checkmark)$ & \\
\hline 400 & 4 & 1 & 2.80 & -3.68 & 0.70 & 17.0 & -56.4 & 13.5 & 240.9 & -226.8 & 101.3 & 188.5 & - & $(\mathscr{\checkmark})$ & $(\times)$ & Incomplete $^{c}$ \\
\hline \multirow[t]{2}{*}{400} & 4 & 2 & 3.16 & -4.36 & 0.65 & 41.9 & -23.2 & 13.9 & 16.3 & -548.2 & 146.3 & 188.6 & - & $(\mathcal{\checkmark})$ & $(\times)$ & Incomplete $^{c}$ \\
\hline & & & & & & & & & & \multicolumn{2}{|c|}{ Total line $\mathrm{km}$} & 1633.2 & 815.9 & & & \\
\hline
\end{tabular}

For direct comparison, the data from each pass were trimmed to the portion of the line that has valid data from both systems.

Shortened because of air traffic.

Incomplete.

${ }^{\mathrm{d}}$ Vertical line deviation. 
Figure 4. The rms (top) and Green and Lane (bottom) gravity noise estimates for different low-pass filters and lines. Left column (a and c) shows AIRGrav results; right column (b and d) shows GT-1A results. The upper row ( $a$ and $b$ ) shows gravity noise estimated from the rms of the differences between all reflights divided by $\sqrt{2}$. The lower row (c and d) shows gravity noise estimated using the Green and Lane (2003) method.

Figure 5. Comparison between conventional $(\mathrm{rms} / \sqrt{2})$ and Green and Lane (2003) noise estimates averaged from $10^{4}$ synthetic data sets versus number of reflights (passes).

Figure 6. Averaged power spectral density estimates of lines used for noise estimate (Figure 4). Power spectra for the 100-s filtered data are calculated using the multitaper method (Thomson, 1982). Line 100 was excluded because it is too short $(24 \mathrm{~km})$ for computing a power spectrum. (a) Entire spectrum (0-800 s) and (b) expanded spectrum (50-200 s) around the cutoff wavelength (100 s) of the low-pass filter. a) Low-pass filter cutoff length (s)

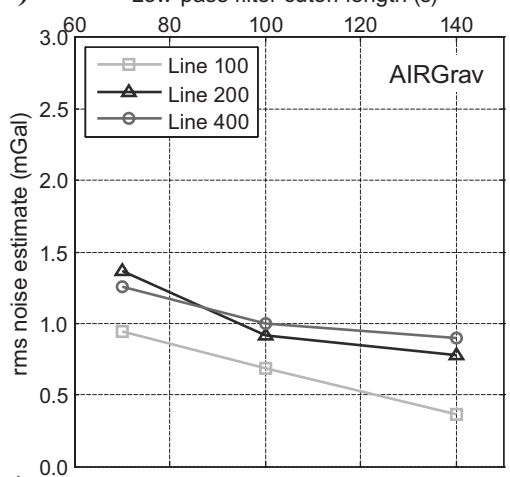

c) 3 .

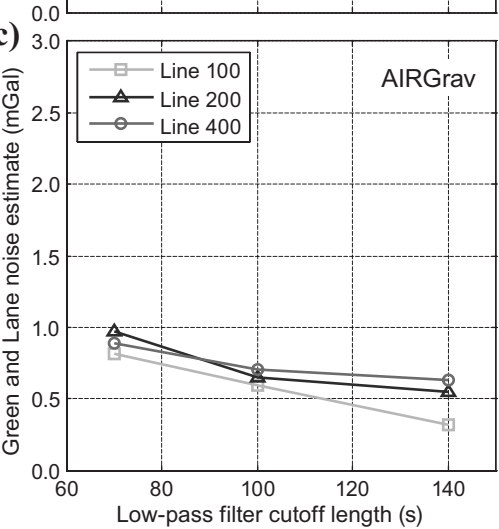

b) Low-pass filter cutoff length (s)

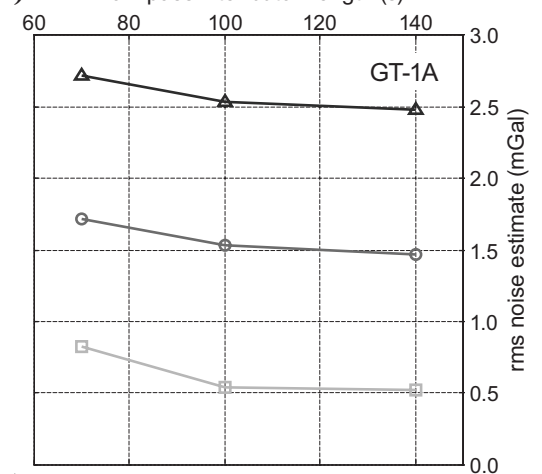

d)
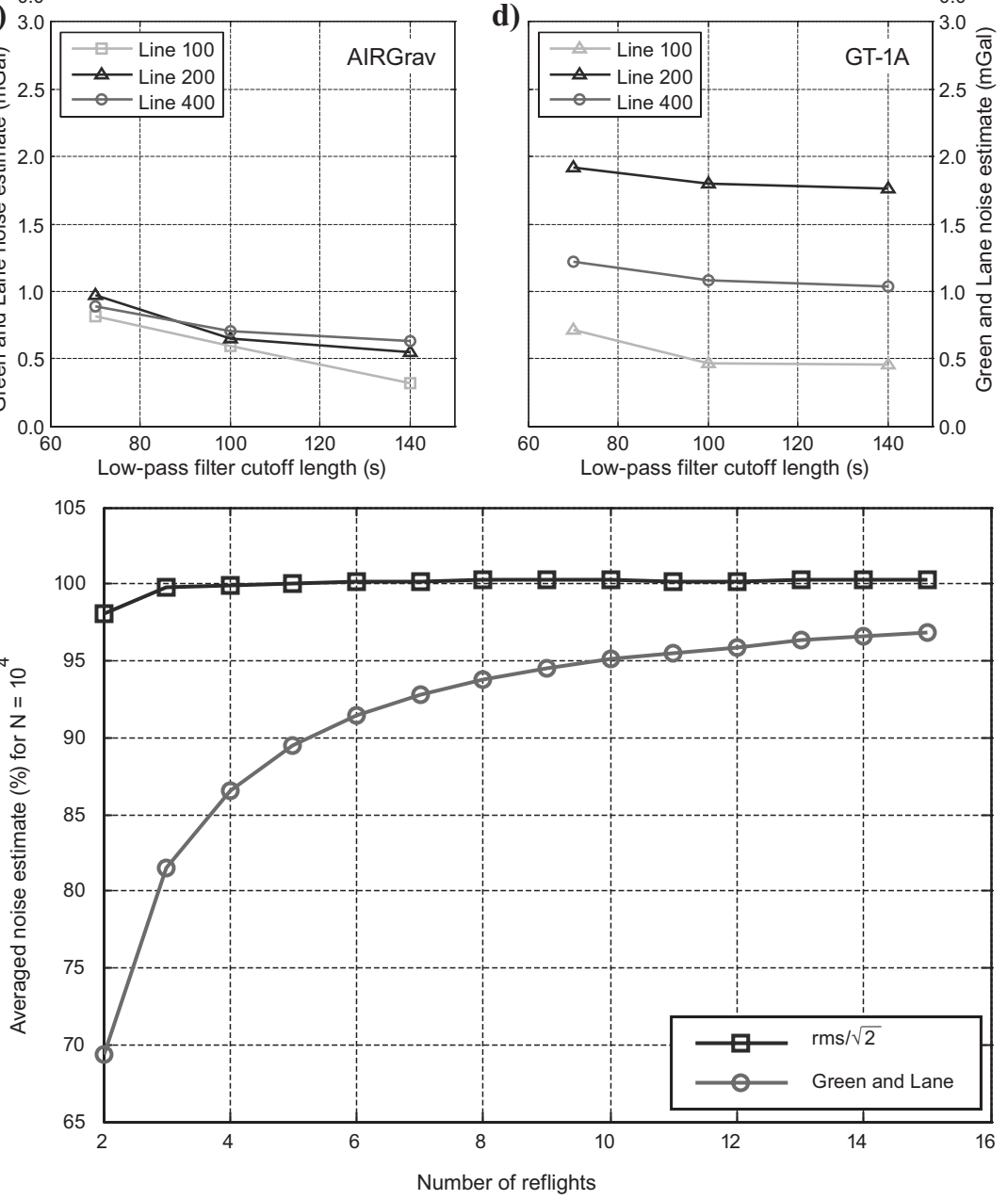

a)

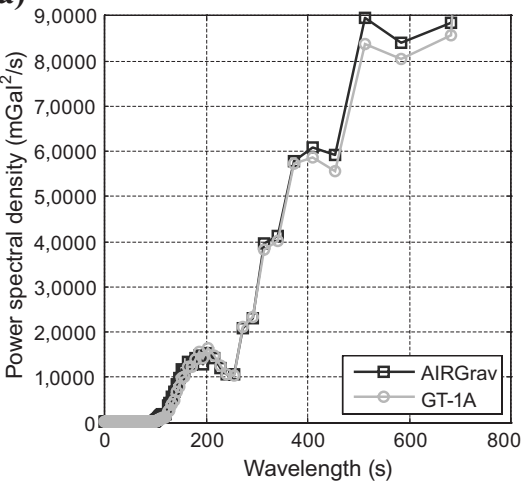

b)

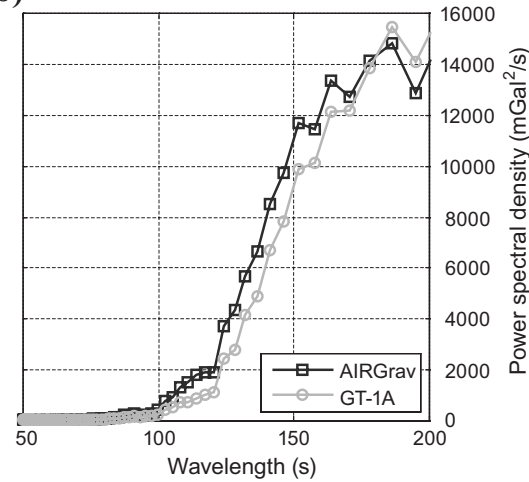


sine taper low-pass filter. Thus, the lower noise estimates of the AIRGrav system are not a result of the different low-pass filters applied to suppress high-frequency noise. On the contrary, the AIRGrav system shows lower noise despite the fact that the cosine taper low-pass filter passes more high-frequency signal and thus noise than the GT-1A 100-s Kalman filter.

\section{Impact of line deviation on noise estimates}

Although the direct comparison above is an estimate of the relative accuracy and resolution between the two systems, the estimates of differences between reflights do not necessarily reflect system noise alone. Several factors contributing to the noise in the data set are not related to the accuracy of the gravimeter systems.

The free-air gravity field over the Rocky Mountains is dominated by large horizontal and vertical gradients. Typically, horizontal gradients are on the order of $5-10 \mathrm{mGal} / \mathrm{km}$ and vertical gradients are $\pm 5-10 \mathrm{mGal} / \mathrm{km}$ with occasional values up to $\pm 20 \mathrm{mGal} / \mathrm{km}$ at flight elevation (Canadian Geodetic Information System, 2008). Over the Turner Valley, both horizontal and vertical gradients are between 1 and $2 \mathrm{mGal} / \mathrm{km}$. In regions with large horizontal gradients $(10 \mathrm{mGal} / \mathrm{km})$, a typical horizontal line deviation of $\pm 40 \mathrm{~m}$ can result in differences between reflights of up to $0.8 \mathrm{mGal}$. These spatial variations in the gravity field are resolved by the gravimeters but cannot be removed by processing. This effect is seen in the test-line data set because the aircraft was not equipped with a pilot guidance system and the effect would not be so evident in a typical airborne gravity survey. Vertical deviation from the target flight elevation can be removed by upward and downward continuation of the profile data to the target flight elevation; however, significant differences can remain in the gravity measured at different flight elevations. Additional operational aspects that contribute to the overall noise level are discussed in the section on operational considerations and accuracy.

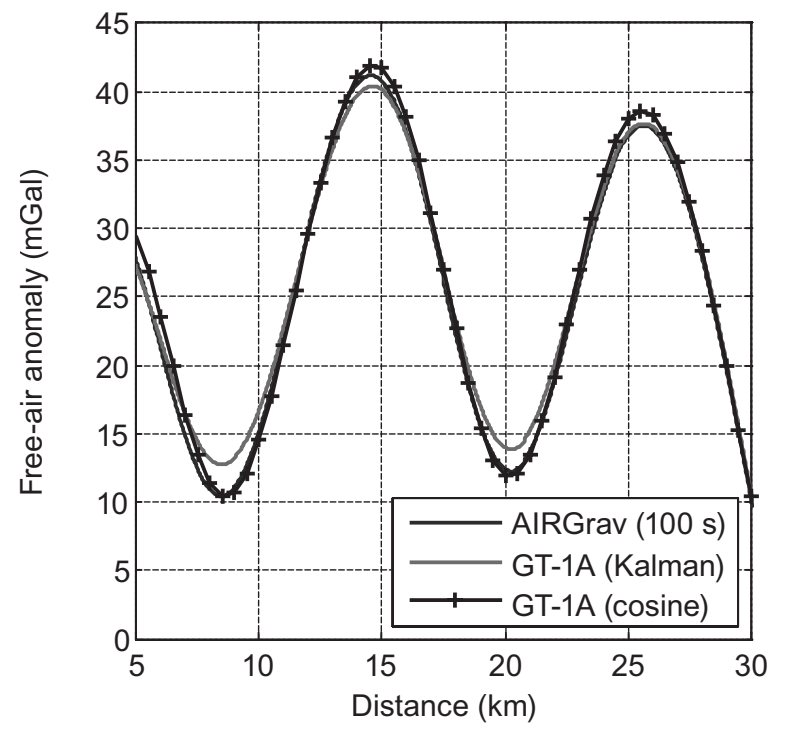

Figure 7. Southern portion of line 400, flight 3, pass 1 between 5 and $30 \mathrm{~km}$. For location, see Figures 1 and 3. The 100-s Kalman filtered gravity of the GT-1A system produces smaller peak-to-peak amplitudes than the AIRGrav system, consistent with the smaller amplitudes in the averaged power spectrum. Filtering the GT-1A raw gravity with the 100-s cosine taper increases the GT-1A amplitudes to the AIRGrav levels.

\section{COMPARISON WITH GROUND GRAVITY DATA}

The accuracy and external consistency of both systems can be estimated from comparisons with ground gravity data. Figure 8a shows the locations of ground and airborne gravity data along a 30 -km-long segment of line 200 near Turner Valley (Peirce et al., 2002). The ground gravity data along this profile have been upward continued to flight elevation and low-pass filtered with the same filters used for airborne data for direct comparison. The ground gravity data were compared to an average of 50 passes of the same line with an AIRGrav system during a previous survey (Sander et al., 2002). Because of the substantial difference in flying speed between the averaged AIRGrav data $(50 \mathrm{~m} / \mathrm{s})$ and our survey $(75 \mathrm{~m} / \mathrm{s})$, a direct comparison between these data sets is impossible.

Figure $8 \mathrm{~b}$ shows the differences between the averaged AIRGrav data, acquired at $50 \mathrm{~m} / \mathrm{s}$ flying speed, and the ground gravity data low-pass filtered with a 70-s cosine taper. The rms difference between the data sets is $0.44 \mathrm{mGal}$ for the 70 -s filter and $0.38 \mathrm{mGal}$ for the 100-s data (Figure 8). For the AIRGrav system, the rms difference between the ground gravity data and four passes of line 200 during our survey ranges from 1.1 to $0.7 \mathrm{mGal}$ (70-140 s) (Figure 9). The rms difference for the GT-1A system for the identical reflights ranges from 1.6 to $1.0 \mathrm{mGal}(70-140 \mathrm{~s})$. Pass 2/flight 2 and pass 2/flight 4 (dashed lines) are excluded from the analysis for both the AIRGrav and GT-1A systems because of the large vertical and horizontal line deviations that result in significant differences between the airborne and ground gravity data which are not related to the accuracy of the gravimeter systems. Figure 9 shows the typical decrease of noise in airborne gravity data with longer cutoff wavelengths and smaller differences between the AIRGrav and ground data compared to differences between the GT-1A and ground data.

\section{OPERATIONAL CONSIDERATIONS AND ACCURACY}

In addition to installing both gravimeters on a raised rack, other factors specific to this test program may have contributed to the overall noise in the data. The survey design and mission profiles for the test flight program differ from typical exploration surveys and reflect the demands of survey flights for research applications in a remote polar environment. Aerogeophysical surveys of this kind often cover large areas with long baselines up to $1000 \mathrm{~km}$ or more for differential GPS positioning (e.g., Brozena et al., 2003; Studinger et al., 2004; Studinger et al., 2006). For this test program, the maximum horizontal distance between the GPS receivers on the aircraft and the base stations was $250 \mathrm{~km}$ for the test flights and is still longer than for most exploration surveys. The accuracy of differential positioning decreases with the length of the base line. The uncertainty in positioning limits the ability to separate gravitational from nongravitational accelerations and thus contributes to the overall noise in the data. In addition to the horizontal distance, the vertical distance of up to $2400 \mathrm{~m}$ between base stations and flight elevation will result in a systematic error in the tropospheric path delay that will add considerable uncertainty to vertical-position estimates (e.g., Klingelé et al., 1997).

In polar regions, the short summer season and challenging logistics often dictate flight operations and limit the opportunity to refly survey lines. For this reason, the performance and reliability of a system in turbulent flight conditions, such as encountered over the Rocky Mountains during the test flights, is critical to determine the 
a)

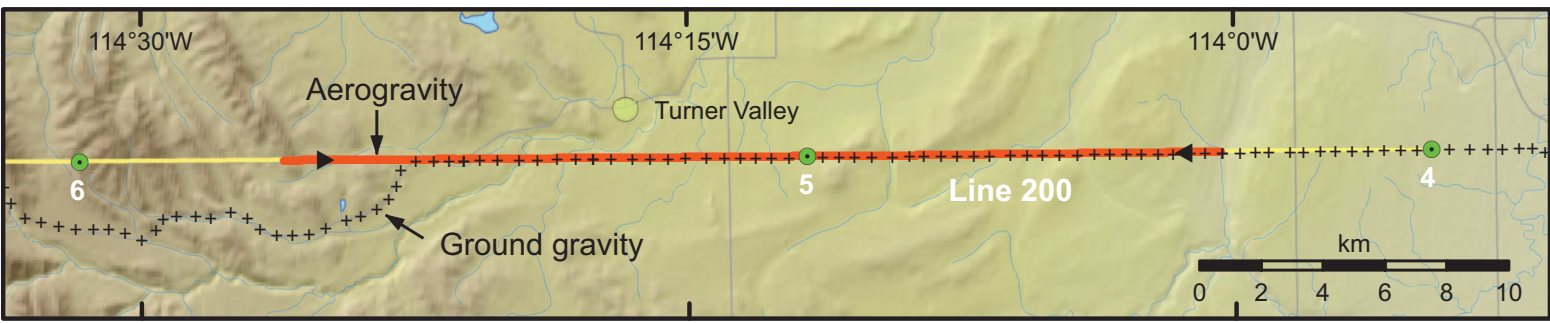

b)

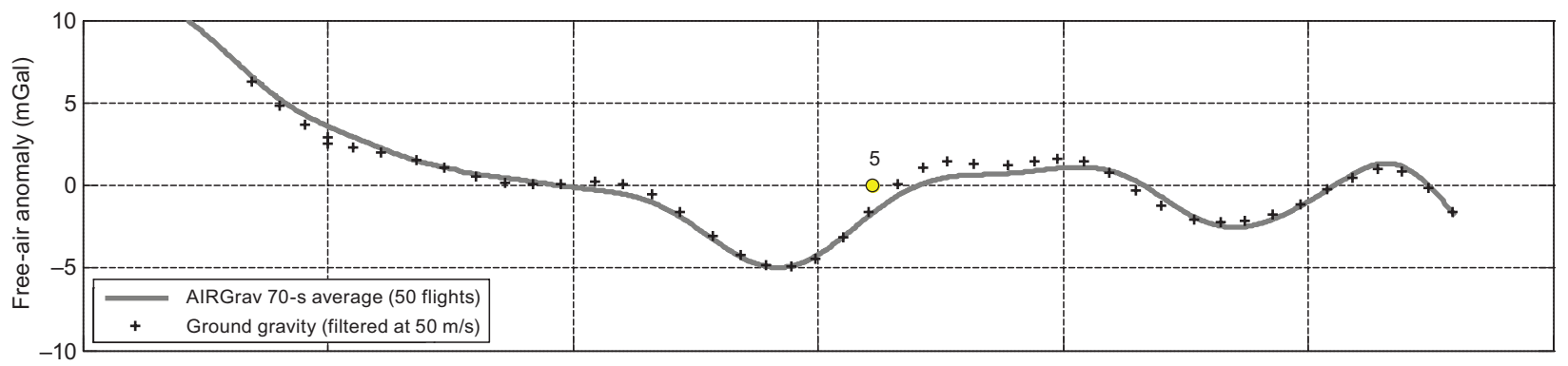

c)

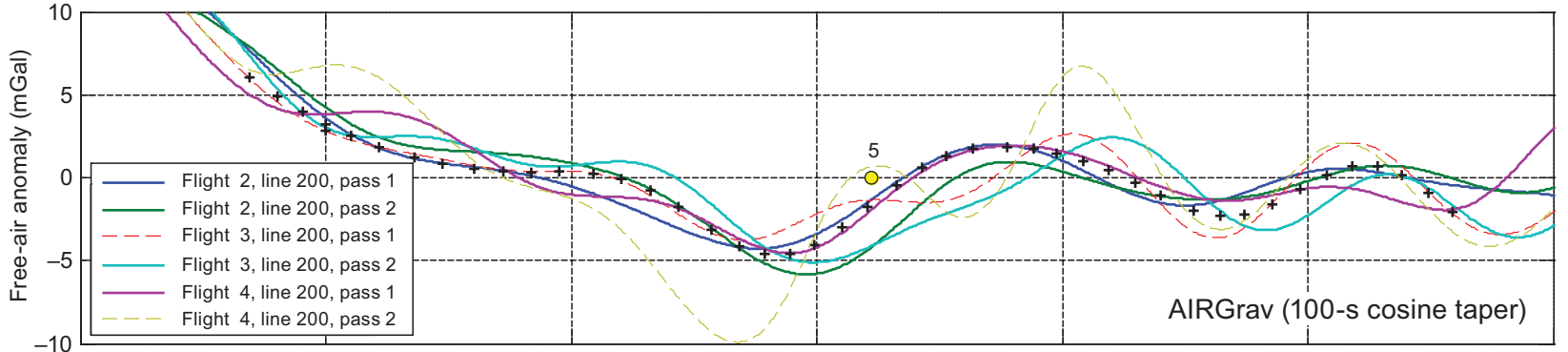

d)

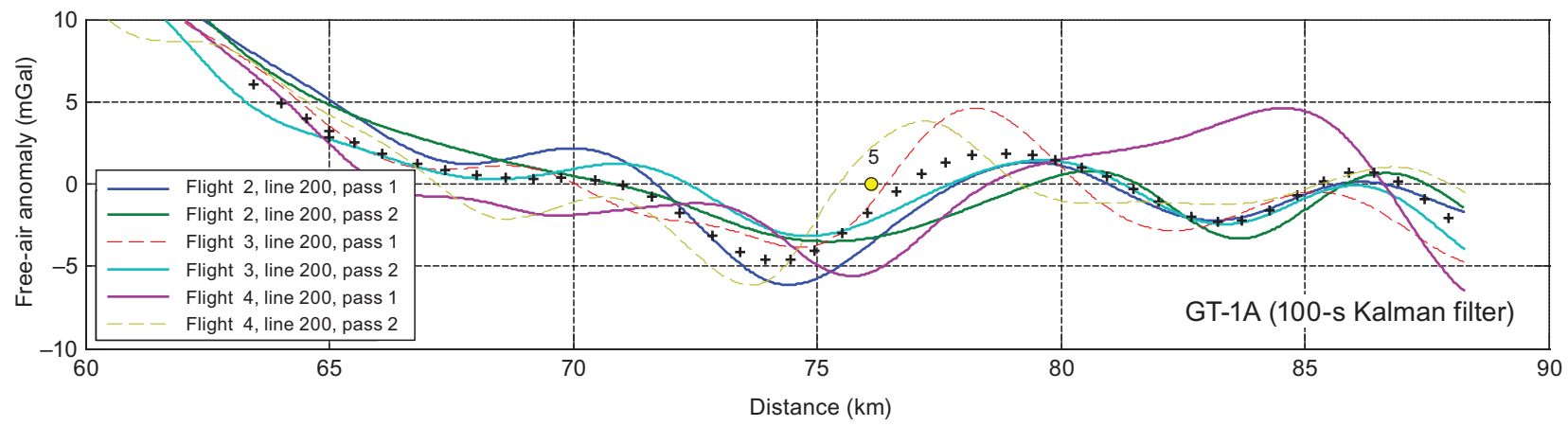

Figure 8. Comparison of ground and airborne gravity data along a 30-km-long segment of line 200 near Turner Valley. (a) Location of ground gravity data is from Peirce et al. (2002) (crosses); 50 averaged passes of AIRGrav data are from Sander et al. (2002) (solid red line). Black triangles mark location of profiles in (b-d) from 60 to $90 \mathrm{~km}$. For map legend, see Figure 1. (b) Comparison of previous AIRGrav data, averaged over 50 passes flown at $50 \mathrm{~m} / \mathrm{s}$, with upward-continued and low-pass filtered ground gravity data. (c) Comparison between AIRGrav and ground data. (d) Comparison between GT-1A and ground data. Pass 2 (flight 2) and pass 2 (flight 4) (dashed lines) are excluded from the analysis for both systems because of the large vertical and horizontal line-track deviations. 


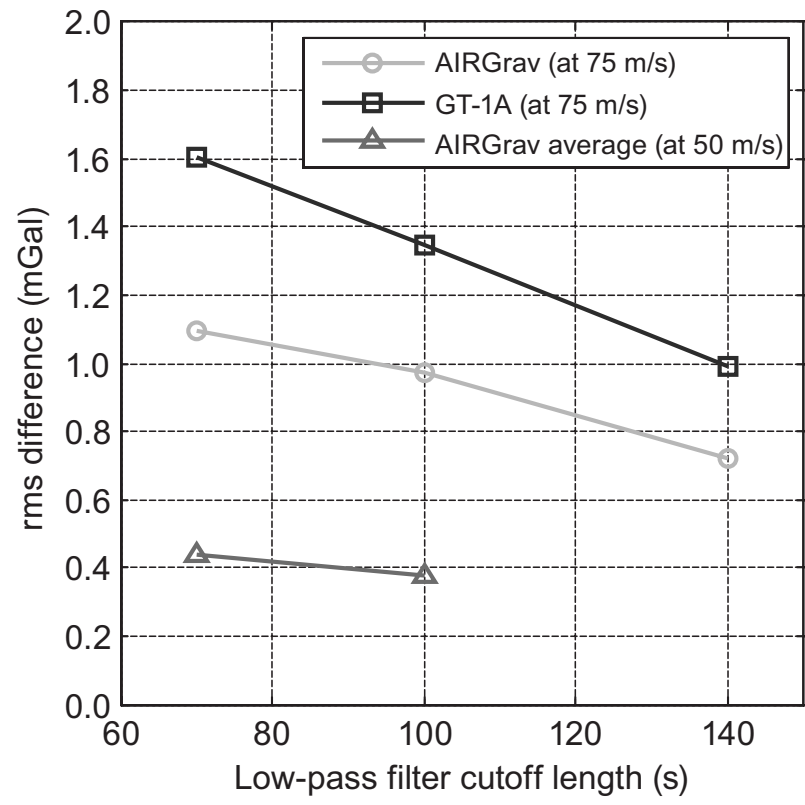

Figure 9. The rms difference between ground and airborne gravity data for three filter cutoff lengths. The difference is calculated along a 30-km-long segment of line 200 near Turner Valley (Figure 8).

suitability of an airborne gravity system for polar applications. During the test flights, the AIRGrav system produced more than 1600 line-km of acceptable data, but the GT-1A often encountered conditions that exceeded the operational limit for vertical accelerations and produced only slightly more than 800 line-km of usable data on the same flights (Table 1). Furthermore, the much shorter lead-in distance for the AIRGrav system $(3 \mathrm{~km})$ compared to the GT-1A $(8 \mathrm{~km})$ has a significant impact on fuel requirements and the logistical scope and cost of surveys in the remote polar regions.

\section{CONCLUSIONS}

We have compared the relative performance and accuracy of a Sander Geophysics AIRGrav system and a Canadian Micro Gravity GT-1A system in side-by-side testing. The purpose of the test program was to evaluate the suitability of these systems for research applications in the polar environment. Survey design, mission profiles, and demands on the performance of an airborne gravimeter are different for the remote polar environment than for most commercial exploration surveys. Both systems are capable of draped flying of airborne gravity, allowing broader potential applications for polar use compared to the previously used BGM-3 and LaCoste \& Romberg gravimeters. Both systems could provide the academic community with a tremendous increase in accuracy and horizontal resolution that will enable major advances in understanding the subglacial environment. Compared to the GT-1A system, the AIRGrav system has a lower noise level and higher accuracy and is less sensitive to changing flight conditions — in particular, vertical accelerations during turbulent flights.

\section{ACKNOWLEDGMENTS}

The gravimeter test flights could not have been possible without the support of many people. We would like to thank all personnel from Sander Geophysics Ltd. who were involved in preparing the test flights, field work, and reduction of GPS and gravity data to the free-air stage. Particular thanks go to Stephen Ferguson and the members of the field crew, Stefan Elieff, Eric Desaulniers, and François Bélanger. Wayne Hewison from Canadian Micro Gravity Ltd. is thanked for field work and data reduction and Helen Tuckett for reducing the final data sets. We thank John Peirce and GEDCO for providing a digital version of the ground gravity data along their test line in Turner Valley. Ken Copiak from Kenn Borek Air Ltd. spent long hours with us in the hangar during the installation and testing in Calgary and is thanked for tremendous support of the project. The support of Kenn Borek pilots Jim Haffey, Matt Colistro, Rob Leach, Wally Dobchuck, and Travis Goetzinger was crucial for the success of this project. Tom Quinn from VECO Polar Resources is thanked for coordinating the logistics. The staff at Eureka Weather Station is thanked for their hospitality and generous science support. Funding for this work was provided by Major Research Instrumentation grant ANT 06-19457 from the U.S. National Science Foundation to the Lamont-Doherty Earth Observatory of Columbia University. This is LDEO contribution 7156.

\section{REFERENCES}

Aleshkova, N. D., A. V. Golynsky, R. G. Kurinin, and V. S. Mandrikov, 2000, Gravity mapping in the southern Weddell Sea region (explanatory note for free-air and Bouguer anomalies maps): Polarforschung, 67, 163-177.

Argyle, M., S. Ferguson, L. Sander, and S. Sander, 2000, AIRGrav results: A comparison of airborne gravity data with GSC test site data: The Leading Edge, 19, 1134-1138.

Bell, R. E., J. M. Brozena, W. F. Haxby, and J. L. LaBrecque, 1990, Continental margins of the western Weddell Sea: Insights from airborne gravity and Geosat-derived gravity: Antarctic Research Series, 50, 91-102.

Bell, R. E., V. A. Childers, R. A. Arko, D. D. Blankenship, and J. M. Brozena, 1999, Airborne gravity and precise positioning for geologic applications: Journal of Geophysical Research, 104, 15281-15292.

Blankenship, D. D., D. L. Morse, C. A. Finn, R. E. Bell, M. E. Peters, S. D Kempf, S. M. Hodge, M. Studinger, J. C. Behrendt, and J. M. Brozena, 2001, Geologic controls on the initiation of rapid basal motion for the ice streams of the southeastern Ross Embayment: A geophysical perspective including new airborne radar sounding and laser altimetry results: Antarctic Research Series, 77, 105-122.

Boebel, T., 2000, Airborne topography and gravimetry: System and application to Fram Strait, Svalbard, and northeast Greenland: Reports on Polar Research, 366, 1-129.

Brozena, J. M., V. A. Childers, L. A. Lawver, L. M. Gahagan, R. Forsberg, J. I. Faleide, and O. Eldholm, 2003, New aerogeophysical study of the Eurasia Basin and Lomonosov Ridge: Implications for basin development: Geology, 31, 825-828.

Brozena, J. M., J. L. Jarvis, R. E. Bell, D. D. Blankenship, S. M. Hodge, and J. C. Behrendt, 1993, CASERTZ 91-92: Airborne gravity and surface topography measurements: Antarctic Journal of the United States, 28, 1-3.

Brozena, J. M., J. L. LaBrecque, R. E. Bell, C. A. Raymond, and M. F. Peters, 1987, An airborne gravity study of the western Weddell Sea: Eos Transactions, 68 , no. 44, 1456.

Canadian Geodetic Information System, 2008, Gravity data: Geoscience Data Repository, Geodetic Survey Division, Earth Sciences Sector, Natural Resources Canada, Government of Canada, http://gdrdap.agg.nrcan.gc.ca/geodap/home/, accessed April 21, 2008.

Damaske, D., and M. McLean, 2005, An aerogeophysical survey south of the Prince Charles Mountains, east Antarctica: Terra Antartica, 12, no. 2 87-98.

Gabell, A., H. Tuckett, and D. Olson, 2004, The GT-1A mobile gravimeter: Australian SEG Airborne Gravity Workshop, http://www.ga.gov.au/ servlet/BigObjFileManager?bigobjid=GA4755, accessed April 21, 2008.

Green, A., and Lane, R., 2003, Estimating noise levels in AEM data: 16th Geophysical Conference and Exhibition, Australian SEG, Extended Abstracts.

Jones, P. C., A. C. Johnson, R. R. B. von Frese, and H. Corr, 2002, Detecting rift basins in the Evans ice stream region of west Antarctica using airborne gravity data: Tectonophysics, 347, no. 1-3, 25-41

Klingelé, E. E., M. Cocard, H. G. Kahle, and M. Halliday, 1997, Kinematic GPS as a source for airborne gravity reduction in the airborne gravity survey of Switzerland: Journal of Geophysical Research, 102, 7705-7715.

McLean, M., and G. Reitmayr, 2005, An airborne gravity survey south of the Prince Charles Mountains, east Antarctica: Terra Antartica, 12, no. 2, 
99-108.

Peirce, J. W., S. Sander, R. A. Charters, and V. Lavoie, 2002, Turner Valley, Canada - A case history in contemporary airborne gravity: Canadian Society of Exploration Geophycists Convention, Expanded Abstracts.

Sander, S., M. Argyle, S. Elieff, S. Ferguson, V. Lavoie, and L. Sander, 2004, The AIRGrav airborne gravity system: Australian Society of Exploration Geophysicists Airborne Gravity Workshop, http://www.ga.gov.au/servlet/ BigObjFileManager?bigobjid=GA4754, accessed April 21, 2008.

Sander, S., S. Ferguson, L. Sander, V. Lavoie, and R. A. Charters, 2002, Measurement of noise in airborne gravity data using even and odd grids: First Break, 20, 524-527.
Studinger, M., R. E. Bell, W. R. Buck, G. D. Karner, and D. D. Blankenship, 2004, Sub-ice geology inland of the Transantarctic Mountains in light of new aerogeophysical data: Earth and Planetary Science Letters, 220, 391408.

Studinger, M., R. E. Bell, P. G. Fitzgerald, and W. R. Buck, 2006, Crustal architecture of the Transantarctic Mountains between the Scott and Reedy Glacier Region and South Pole from aerogeophysical data: Earth and Planetary Science Letters, 250, 182-199.

Thomson, D. J., 1982, Spectrum estimation and harmonic analysis: Proceedings of the IEEE, 70, 1055-1096. 